\title{
GRP78 in lung cancer
}

\author{
Shengkai Xia ${ }^{1 \dagger}$, Wenzhe Duan ${ }^{1 \dagger}$, Wenwen Liu ${ }^{2+}$, Xinri Zhang ${ }^{3^{*}}$ and Qi Wang ${ }^{1,2^{*}}$ (B)
}

\begin{abstract}
Glucose-regulating protein 78 (GRP78) is a molecular chaperone in the endoplasmic reticulum (ER) that promotes folding and assembly of proteins, controls the quality of proteins, and regulates ER stress signaling through $\mathrm{Ca}^{2+}$ binding to the ER. In tumors, GRP78 is often upregulated, acting as a central stress sensor that senses and adapts to changes in the tumor microenvironment, mediating ER stress of cancer cells under various stimulations of the microenvironment to trigger the folding protein response. Increasing evidence has shown that GRP78 is closely associated with the progression and poor prognosis of lung cancer, and plays an important role in the treatment of lung cancer. Herein, we reviewed for the first time the functions and mechanisms of GRP78 in the pathological processes of lung cancer, including tumorigenesis, apoptosis, autophagy, progression, and drug resistance, giving a comprehensive understanding of the function of GRP78 in lung cancer. In addition, we also discussed the potential role of GRP78 as a prognostic biomarker and therapeutic target for lung cancer, which is conducive to improving the assessment of lung cancer and the development of new therapeutic interventions.
\end{abstract}

Keywords: GRP78, Lung cancer, Endoplasmic reticulum, Unfolded protein response (UPR), Autophagy

\section{Introduction}

Lung cancer is the leading cause of cancer-related mortality in men and the second most diagnosed malignancy in women, only after breast cancer [1]. In 2018, lung cancer accounted for more than 1.8 million deaths worldwide [2], with an overall 5-year survival rate of approximately $19 \%$ [3]. The survival rates of lung cancer patients are largely dependent on the early diagnosis and intervention of the disease. An improved understanding of the molecular mechanisms involved in the development and progression of lung cancer, along with the development of drug resistance, will aid in the discovery of new treatment strategies.

\footnotetext{
*Correspondence: ykdzxr61@163.com; wqdlmu@163.com

'Shengkai Xia, Wenzhe Duan and Wenwen Liu contributed equally to this work

${ }^{1}$ Department of Respiratory Medicine, The Second Hospital, Dalian Medical University, No. 467 Zhongshan Road, Dalian 116023, China ${ }^{3}$ Department of Respiratory and Critical Care Medicine, The First Hospital, Shanxi Medical University, No. 85 Jiefang South Road, Taiyuan 030001, Shanxi, China

Full list of author information is available at the end of the article
}

Glucose-regulated protein 78 (GRP78), also known as immunoglobulin heavy chain binding protein (BiP), together with GRP94 and GRP58, was discovered as a cellular protein inducible by glucose starvation in the late 1970s [4]. GRP78 has a signal peptide sequence that acts as a molecular chaperone on the endoplasmic reticulum (ER). It is involved in the proper folding and assembly of proteins, proteasome degradation of misfolded proteins, ER and $\mathrm{Ca}^{2+}$ binding, and the activation of transmembrane ER stress sensors [5]. Under ER stress, activated GRP78-related unfolded protein response (UPR) restores cell homeostasis or induces cell death in chronically damaged cells [6]. As such, GRP78 is overexpressed in lung cancer $[7,8]$, and is widely involved in the promotion of tumor proliferation, metastasis, drug resistance, and apoptosis $[9,10]$.

In recent years, new insights into the chronic ER stress experienced by cancer cells, along with the importance of GRP78 or GRP78-related UPR in tumor progression, have stimulated the exploration of GRP78 and UPR as potential therapeutic targets. In this review, we describe the role of GRP78 in the tumorigenesis, apoptosis, autophagy, invasion, and metastasis, and drug 
resistance of lung cancer, as well as its clinical implications as a potential prognostic and therapeutic target of this disease.

\section{GRP78 in UPR and stress response}

The ER is a perinuclear organelle, involved in the synthesis and folding of secreted nuclear and membrane proteins. These proteins are then transported to the cell surface through the cross-Golgi network [11]. However, the function of the ER can be hindered by several factors, such as hypoxia, nutrient/glucose deficiency, oxidative stress, $\mathrm{Ca}^{2+}$ depletion and certain viral infections [12]. ER stress is induced by alterations in its folding abilities, resulting in an imbalance of protein homeostasis. In return, the proteins become misfolded, which has detrimental effects on their normal cellular function. To avert this situation and re-establish homeostasis, the cell triggers the UPR to activate several biochemical mechanisms and alleviate the ER stress. In situations where the UPR cannot re-establish homeostasis, cellular apoptotic pathways are activated (Fig. 1) [12-14].

IRE1 (inositol-requiring enzyme 1), PERK (PRKR-like ER kinase), and ATF6 (activating transcription factor 6) are the three major ER transmembrane proteins involved in the UPR signaling cascade. GRP78, which binds these three proteins in ER through their lumen domains, is considered to be the main regulatory protein of UPR [4]. In the normal state, GRP78 mainly binds to IRE1, PERK, and ATF6 to silence these proteins to prevent UPR signaling. However, GRP78 combines with the misfolded proteins accumulated in the ER under stress conditions to keep the proteins in foldable states and releases three UPR mediators. Next, it releases the three UPR mediators, each of which induces a different signal transduction pathway that mediates the UPR of a particular arm.

IRE1 can dimerize and undergo autophosphorylation when GRP78 releases IRE1, thereby activating its ribonuclease (RNase) $[15,16]$. Next, the mRNA of XBP1 (x-box binding protein) is cleaved, which generates a spliced form of XBP1 (XBP1-s) [17]. XBP-1s upregulates genes that encode ER chaperones and ER-related protein degradation (ERAD) proteins. In addition, it mediates the transcription of XBP-1 in a self-regulated manner [18]. Next, IRE1 activates c-jun n-terminal kinase (JNK) by recruiting tumor necrosis factor (TNF) receptor-related factor 2 (TRAF2), which promotes apoptosis under the extended UPR signaling pathway [19].

PERK acts similarly to IRE1 after the release of GRP78, leading to the dimerization and phosphorylation of the eIF2 promoter (eukaryotic translation initiation factor 2a), which inhibits global protein synthesis [16]. The phosphorylation of eIF2a activates ATF4 (activating transcription factor 4), which controls the expression of UPR target genes related to ERAD, protein folding, amino acid biosynthesis, autophagy, and pro-apoptotic CCAAT/enhancer-binding protein-homologous protein (CHOP) to regulate the UPR [20-23]. CHOP is a characteristic factor of ER stress that causes cellular apoptosis [24]. Besides, PERK inhibits ROS accumulation by phosphorylating and stabilizing NRF2, which regulates the expression of genes containing antioxidant response [25].

After GRP78 is release, ATF6 is transferred to the Golgi complex, where ATF6 is cleaved by the SiP1 (site1-protease) and SiP2 (site-2-protease) proteases, which releases a cytosolic basic leucine zipper (bZIP) domain $[26,27]$. The bZIP domain translocates to the nucleus, promoting the transcription of ERAD genes and XBP1 [28], which further reduces the burden of unfolded proteins and ER stress.

\section{Biological function of GRP78 in lung cancer}

UPR is activated to support tumor survival and development due to the poor tumor vascular hyperplasia and high proliferation, making tumors suffer from various forms of stress. As the main UPR regulatory protein, GRP78 is highly expressed in a variety of tumor cells. In this section, GRP78 has both UPR-dependent and UPRindependent functions, which may help in several aspects of tumor biology, including tumorigenesis, apoptosis, autophagy, invasion, and metastasis, along with chemotherapy resistance (Fig. 2).

\section{Role of GRP78 in tumorigenesis}

In the early stages of tumorigenesis, ER stress increases the expression of GRP78 and other ER chaperone proteins. Compared with normal lung tissues, GRP78 is significantly overexpressed at the mRNA and protein levels of lung cancer tissues. The overexpression of GRP78 in lung cancer tissues is closely related to the differentiation and development of lung cancer [7, 29].

On the one hand, oxidative stress may have profound effects on the function of the ER by interfering with various aspects of protein folding, leading to the induction of the ER stress response [30], but the enhanced activity of GRP78 can relieve oxidative stress, which plays a vital role in protecting cancer cells from oxidative stress-induced cellular damage and cell death [31, 32]. The overexpression of GRP78 induced by this continuous oxidative stress can help cells become more resistant to various stressful challenges, which contributes to the development of tumors. For example, during the entire course of nicotine exposure, nicotine causes an acute increase in reactive oxygen species (ROS), which induces GRP78 upregulation and subsequent PERK phosphorylation, causing ER stress and UPR activation. In return, this produces a favorable microenvironment suitable 


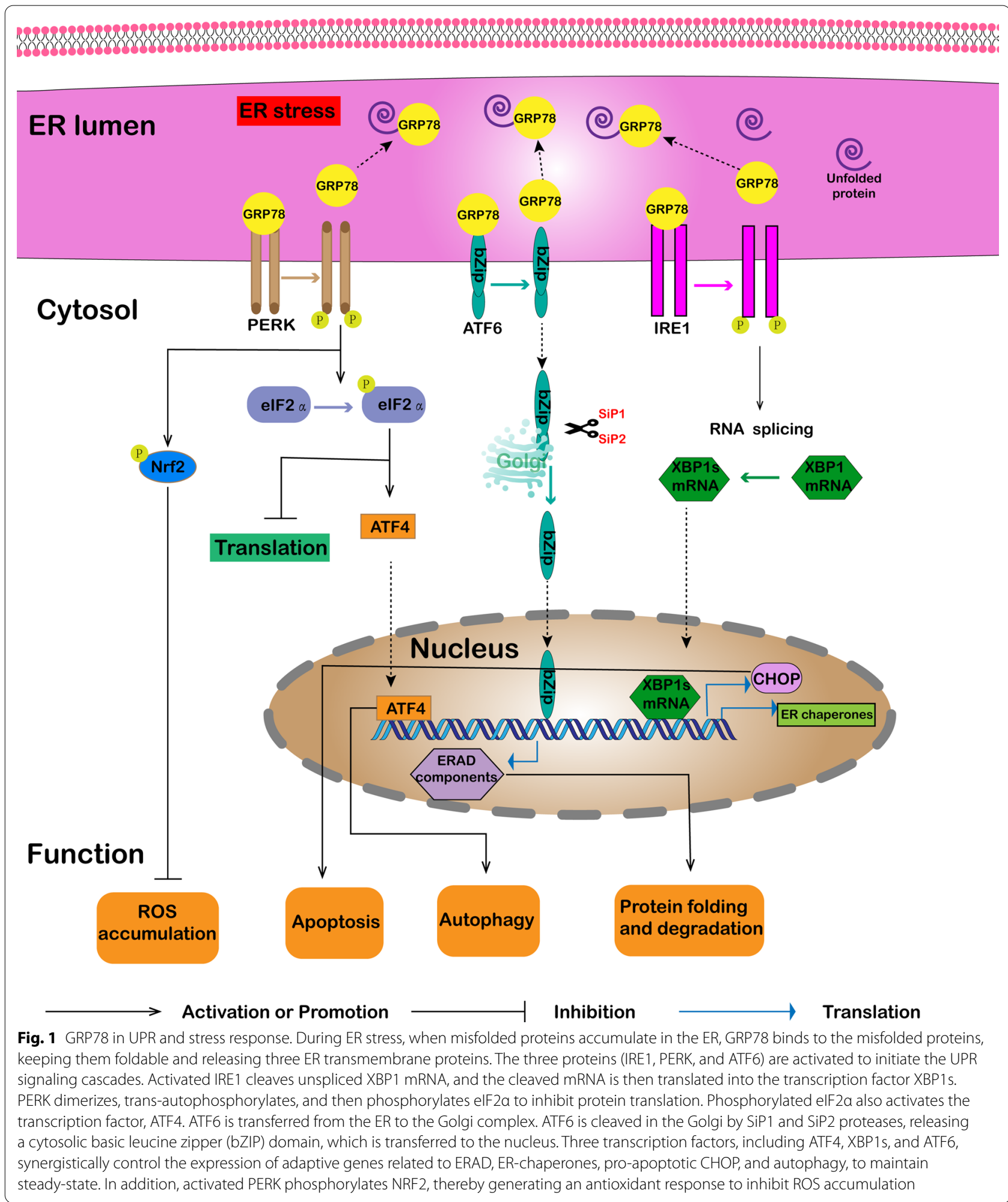

for the development of lung cancer [33]. In microfluidic devices, continuous low flow cigarette exposure to nontumor bronchial epithelial cells in chronic obstructive pulmonary disease (COPD) and lung squamous cell carcinoma patients stimulates ROS production and induces tumor-like transformation of human non-tumor 


\section{Hypoxia, glucose deprivation, low $\mathrm{pH}$, and ROS accumulation}

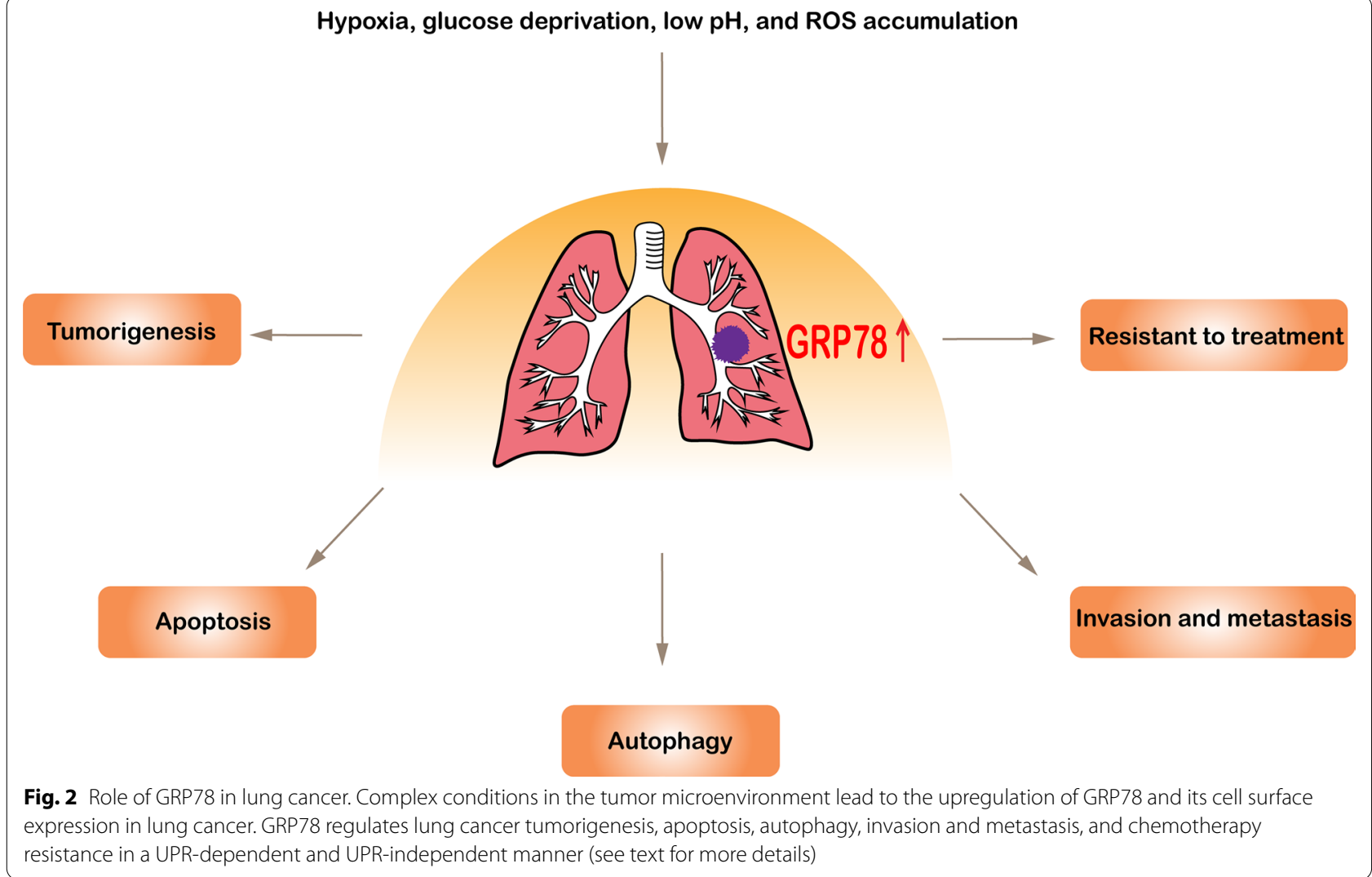

bronchial epithelial cells through GRP78, NF-kB, and PI3K signaling pathways [34].

On the other hand, GRP78 enhances the folding ability of ER protein and protects cells from ER stress-induced cell damage and cell death, which has many effects on tumorigenesis. RRBP1 enhances GRP78 protein expression and regulates UPR, which allows it to adapt to ER stress to maintain the tumorigenicity of lung cancer [35]. OTUD3 plays an oncogenic role in lung cancer cells and promotes the development of lung cancer by directly interacting with GRP78, where OTUD3 deubiquitylates GRP78 and maintains GRP78 stability in vitro and in vivo. An important note is that OTUD3 co-localizes with GRP78 in the cytoplasm, especially in the ER, indicating that it causes carcinogenesis through the ER [36]. These mechanisms suggest that the regulation of GRP78 can impact the degree of ER stress and oxidative stress, which may play a role in the development of lung cancer.

\section{Apoptosis}

Apoptosis is an active and physiological death process that occurs under certain physiological or pathological conditions, controlled by inherent genetic mechanisms. In recent years, several studies have assessed the role of GRP78 in cell apoptosis (Fig. 3).
On the one hand, GRP78 has an important anti-apoptotic function, and several cancer cell lines adapt to chronic stress in the tumor microenvironment via GRP78 upregulation [37, 38]. GRP78 can stabilize mitochondrial permeability, inhibit mitochondrial cytochrome c release, and reduce ER stress-induced apoptosis by maintaining the stability and function of Raf-1 [39]. Ectopic expression of GRP78 can form a complex with caspase-7 and caspase-12 that inhibit the activation of caspase-12-mediated cell death [40]. At the same time, kurarinone induces the apoptosis of A549 cells by inhibiting GRP78 expression and subsequently releasing the inhibition of caspase-12 and caspase-7 [41]. On the other hand, some studies have shown that GRP78 expression is positively correlated with the apoptosis of human lung adenocarcinoma cells [42]. The enhanced activity of GRP78 increases the expression of cleaved caspase-12 and BAX, promoting the apoptosis of A549 cells [43]. $\mathrm{Ca}^{2+}$ imbalance is an important factor that mediates apoptosis. For example, GADD153 and GRP78 are upregulated in response to ER stress, promoting the production and release of $\mathrm{Ca}^{2+}$. Increased $\left[\mathrm{Ca}^{2+}\right]$ induces apoptosis in A549 cells through mitochondrial-dependent pathways, such as upregulated Bax expression and downregulated $\mathrm{Bcl}-2$ expression [44]. In addition, $\mathrm{Ca}^{2+}$ released into the 


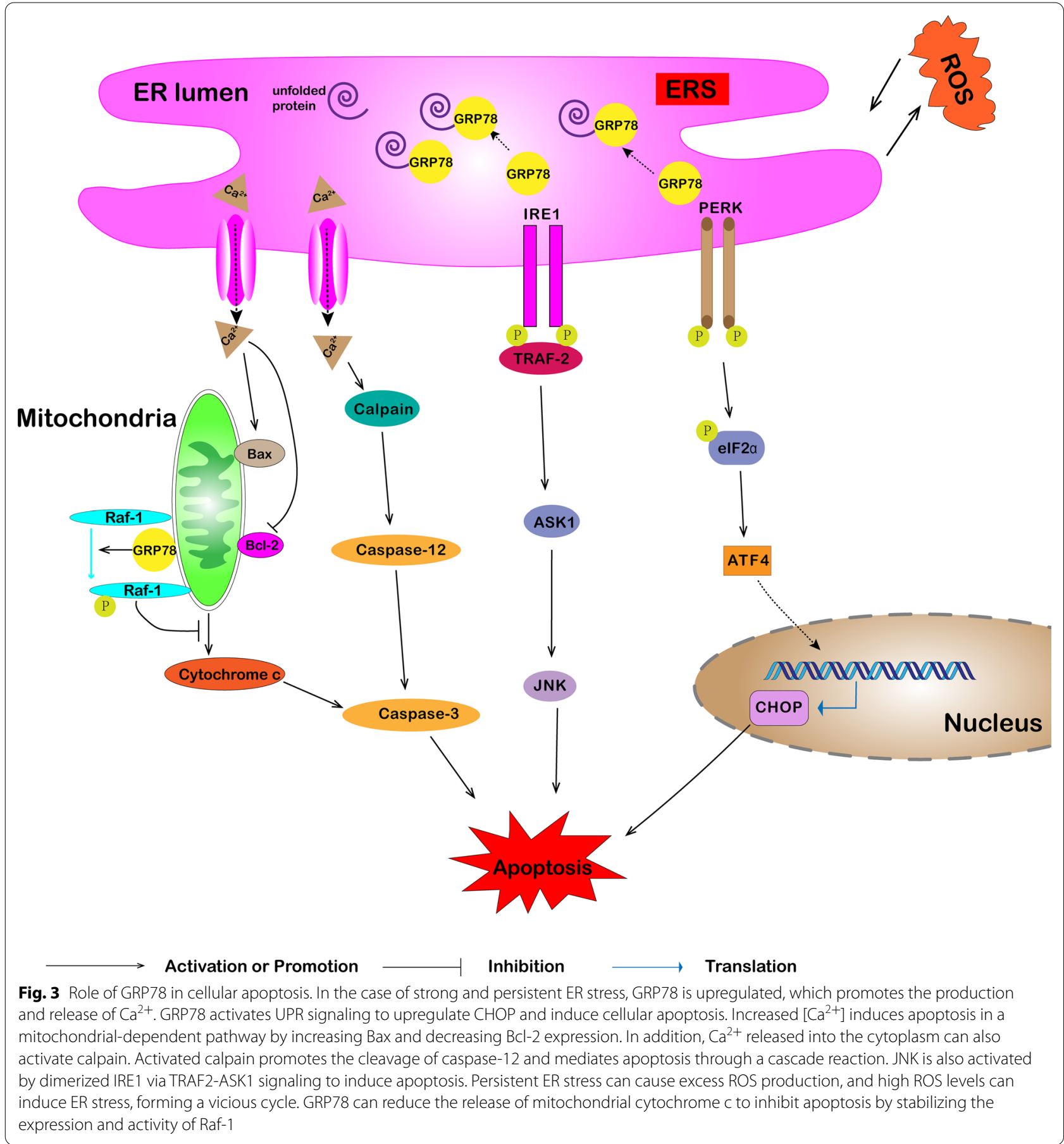

cytoplasm can activate calpain, which is transferred to the ER membrane to promote the cleavage of caspase-12, mediating the apoptosis of lung cancer cells [45].

Multiple studies have shown that GRP78-related ER stress signaling pathways are involved in cancer cell death [46]. For example, GRP78 activates CHOP through the PERK pathway [20-22]. CHOP stimulates the transport of Bax to mitochondria and inhibits the expression of $\mathrm{Bcl}-2$, promoting mitochondrial pathwaymediated apoptosis [45]. The excessive activation of IRE1 can induce apoptosis [47]. ER stress increases the expression of GRP78, CHOP, and IRE1 $\alpha$, in which activated IRE1 $\alpha$ combines with TRAF2, recruits ASK1 to form a complex, and then activates JNK to induce lung 
cancer cell apoptosis [48-50]. In addition, continuous ER stress can increase ROS production, and high ROS levels can induce ER stress, forming a vicious cycle that results in cell apoptosis [51, 52]. Hence, GRP78 is the main protein that regulates the apoptosis of lung cancer cells. On the one hand, GRP78 plays an anti-apoptotic role by inhibiting the functions of apoptosis-related proteins. GRP78 also exerts a pro-apoptotic effect by mediating $\mathrm{Ca}^{2+}$ imbalances and activating the UPR pathway.

\section{Autophagy}

The process of autophagy begins with the isolation of unnecessary by-products or damaged organelles into autophagosomes. Next, the autophagosomes and lysosomes are fused to form autophagolysosomes, which then degrade the internal cargo to provide the cell with its own metabolic requirements, along with the renewal of specific organelles [53]. Autophagy plays both positive and negative roles in promoting the apoptosis of non-small cell lung cancer (NSCLC) cells. In general, the inhibition of autophagy limits the ability of cells to overcome stress and maintain homeostasis [54]. However, there are also examples of autophagy contributing to cell death in lung cancer [55]. There is increasing evidence that ER stress can induce autophagy activation [56-58]. Some studies of lung cancer have shown that autophagy can promote the growth and progression of tumors $[59,60]$. ER stress induces autophagy by activating the PERK-eIF2 $\alpha$-ATF4-CHOP and IRE1-TRAF2JNK signaling axes of UPR, providing a protective effect against $\beta, \beta$-dimethylacrylshikonin (DMAS)-induced apoptosis of human lung adenocarcinoma cells [23]. GRP78 is crucial for autophagy regulation [61]. For example, GRP78 downregulation can block the formation of autophagosomes induced by ER stress [62]. Under acidic conditions, GRP78 knockdown reduces autophagy activation, inhibiting the autophagy-associated cell repair mechanisms in lung cancer cells [63]. In contrast, the hypochlorous acid $(\mathrm{HOCl})$ named probe $\mathrm{ZBM}-\mathrm{H}$ targets $\mathrm{HOCl}$ in the ER, thereby inhibiting the HOCl-induced Lys 353 oxidation of GRP78 and enhancing GRP78 activity. ZBM-H promotes A549 cell autophagy and inhibits lung cancer cell growth through the GRP78/AMPK/mTOR pathway [43]. GRP78, CHOP, and IRE1 are upregulated, followed by the downregulation of the PI3K/AKT/mTOR signaling pathway, which promotes the autophagy of mutant p53-LC cells [64, 65]. Therefore, the life-promoting and death-promoting functions of autophagy in cancer cells are largely dependent on the cell type and stimulus conditions $[66,67]$.

\section{GRP78 promotes the invasion and metastasis of lung} cancer

The metastasis of tumor cells is one of the most important features of malignant tumors. Tumor metastasis relies not only on the changes of tumor cells but also on the interaction between the tumor cells and tumor microenvironment. The role of GRP78 in tumor metastasis is becoming more apparent due to recent findings. GRP78 expression is upregulated in metastatic tumor cell lines, including lung cancer cell lines [68-74]. The downregulation of GRP78 effectively inhibits the invasion of tumor cells in vitro and metastasis of transplanted tumors $[75,76]$. In the next section, we discuss the relevant molecular mechanisms of GRP78-mediated epithelial-mesenchymal transition (EMT) of cancer cells and the interaction between cancer cells and non-cancer cells in lung cancer metastasis.

\section{GRP78 mediates the interactions between lung cancer and tumor microenvironment}

Since solid tumors generally grow faster than the surrounding vasculature, special growth conditions can occur, such as hypoxia, glucose deficiency, and lactic acidosis [77]. Under these stress conditions, the UPR signal is often activated, allowing the microenvironment and tumor cells to adapt to each other. For example, the key ER stress protein BiP/GRP78 interacts with CIM to modulate UPR, enabling lung cancer cells to adapt to the metastatic site microenvironment and acquire the ability to survive and settle at the metastatic site [78]. In addition, non-cancer cells also provide essential support for the growth, angiogenesis, and metastasis of cancer cells (Fig. 4).

Tumor vasculature is critical for tumor growth and metastasis because it provides nutrients and oxygen critical for tumor growth and maintenance. Studies have shown that GRP78 plays an important role in regulating the host vascular system in some tumor microenvironments, including lung cancer $[79,80]$. Conditional heterozygotic knockout of GRP78 in host endothelial cells significantly reduced the angiogenesis and growth of tumors, suggesting that GRP78 is an essential mediator of angiogenesis and regulator of cell proliferation, survival, and migration [81]. GRP78-related UPR is also involved in tumor angiogenesis [82]. Hypoxia and glucose deprivation mediate the upregulation of VEGF-A through IRE1 signaling, forming new blood vessels in A549 lung cancer cells [83]. The pro-angiogenic response driven by IRE1 may be secondary to XBP-1 splicing [84].

Cancer-associated fibroblasts (CAFs) play important roles in the occurrence, protection, and metastasis of cancer [85]. CAFs are known to interact with 


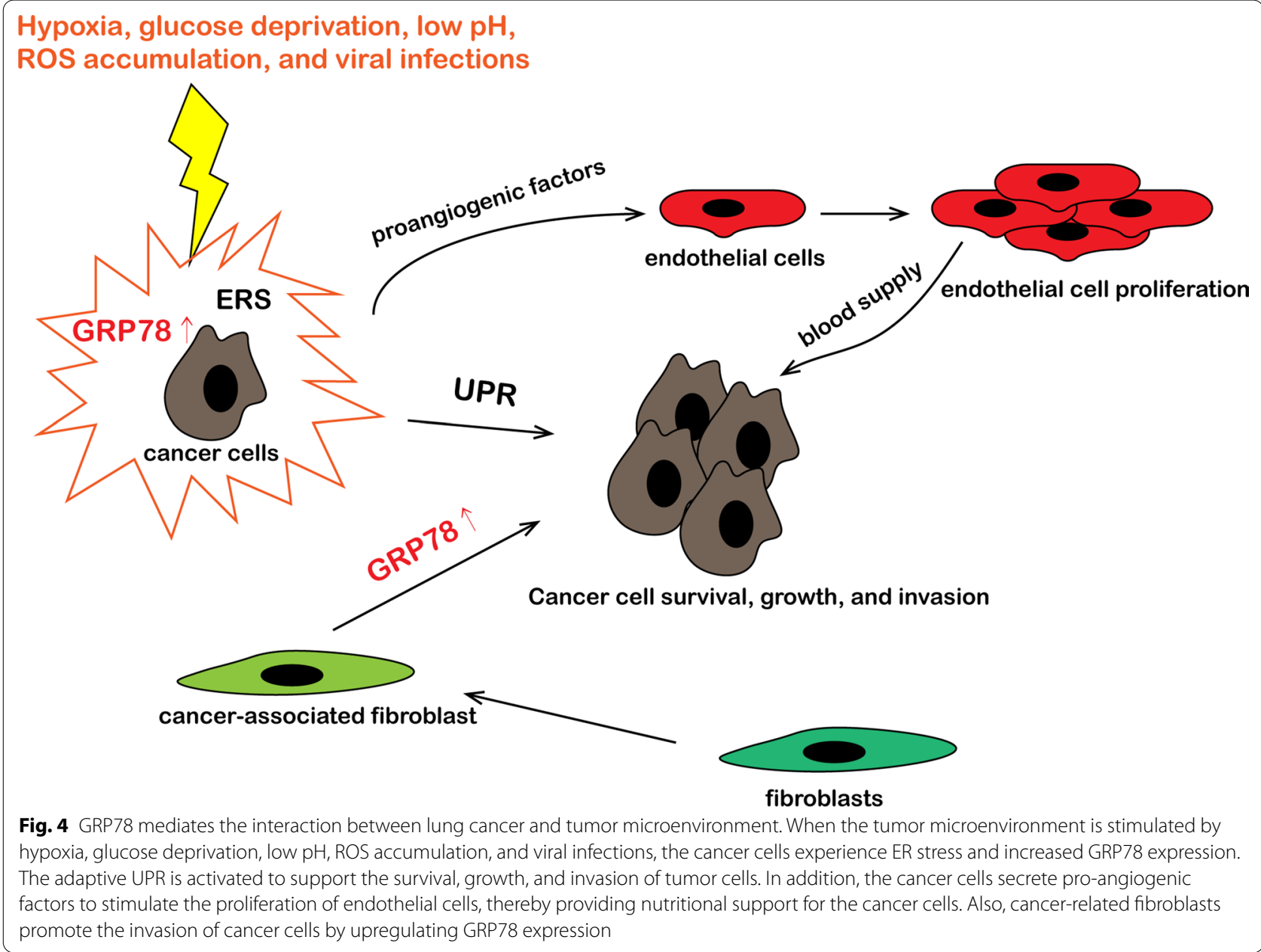

tumor-related immune cells to regulate the microenvironments of tumors [86]. Some studies have shown that GRP78 plays an important role in the differentiation and formation of CAFs, which is conducive to the formation of the tumor microenvironment [87]. In addition, CAFs promote cell invasion in NSCLC cells by upregulating the expression of GRP78 [88].

The role of UPR in the tumor microenvironment suggests that UPR can relieve ER stress at the system level, rather than in a single cellular response. Therefore, it is necessary to understand how UPR, especially GRP78, promotes tumor growth and metastasis by interacting with other cells or microenvironmental components of the tumor. Furthermore, the development of treatments for these effects will improve the therapeutic efficacy and prognosis of patients.

\section{GRP78 mediates epithelial-mesenchymal transition (EMT)}

Angiogenesis provides a way for tumor cells to escape and metastasize to other organs, but tumor cells must acquire an aggressive and migratory phenotype before they can gain access to the surrounding blood vessels. The abnormal activation of EMT causes tumor cells to lose cell-to-cell contact, resulting in an aggressive and migratory phenotype that is favorable for metastasis. The increase in UPR, especially GRP78, has been shown to promote EMT in various cell types, promoting the tumorigenesis and metastasis of lung cancer. Studies have shown that GRP78 overexpression induces cell-matrix adhesion and EMT by driving TGF-TGF-1smad2/3 signaling and integrin-1-FAK signaling, which contribute to the metastasis [89]. Under hypoxic conditions, GRP78 expression in A549 cells significantly increases, mediating hypoxia-induced EMT in A549 cells, which is related to the smad2/3 and SRC/MAPK signaling pathways [90]. Polypeptide $\mathrm{N}$-acetylgalactosaminyltransferase-6 (GALNT6) O-glycosylates and stabilizes GRP78, which promotes EMT by enhancing the MEK1/2/ERK1/2 signaling in lung cancer cells [91]. This shows that part of the reason for GRP78's increased metastatic potential may be its association with EMT. 
GRP78 mediates the resistance of lung cancer to treatment Patients initially respond to chemotherapy drugs, as demonstrated through reductions in tumor size. However, many patients develop resistance to chemotherapies because a small number of cancer cells adapt internally in response to the additional stress caused by chemotherapeutic drugs. The adaptation to chemotherapeutic drugs may be due to factors like enhanced drug efflux, drug activation/inactivation, alternations in drug targets that promote the removal of drug from the tumor, as well as the intrinsic changes of tumor cells, like enhanced stemness [92]. Here, GRP78 is proved to mediate the resistance of lung cancer cells to treatment through UPR and promoting the stemness of cancer cells.

\section{GRP78 mediates lung cancer resistance to treatment through UPR}

The adaptability of using UPR is also a mechanism used to ensure the survival of cancer cells after exposure to chemotherapy drugs. In many cell types, excessive GRP78 reduces apoptosis, alleviates ER stress, and increases the chemo- and radio-resistance of tumor cells [93]. The knockout of GRP78, ATF6, ATF4, and $\mathrm{XBP} 1 \mathrm{~s}$ is related to the mechanism of increasing the sensitivity of cells to chemotherapy drugs [94-96]. Photodynamic therapy (PDT) can upregulate GRP78, which has a cytoprotective effect and makes the cells resistant to PDT [97]. RRBP1 enhances the expression GRP78 to make lung cancer cells resistant to chlamycin, 2-deoxyglucose, and doxorubicin [35]. GRP78 expression is upregulated on the cell surface, which regulates AKT phosphorylation. GRP78 may enable ER stress tolerance (ERST) in lung cancer cell lines to survive more easily under cisplatin treatment than parental cell lines by activating the AKT signaling cascade [98].
GRP78 mediates the resistance of lung cancer to treatment by acquiring stemness

Cancer stem cells may have many characteristics of normal stem cells, including being relatively quiescent, resistance to drugs and toxins by expressing drugresistant molecules, active DNA repair capabilities, and resistance to apoptosis. These properties allow cells to survive chemotherapy and repopulate the tumor [99]. Recent studies have shown that GRP78 on the cell surface (sGRP78) transmits signals to promote epithelialmesenchymal transition and stemness of cancer cells [31, $91,100]$. Compared with other populations in tumors, sGRP78 $^{+}$cells express higher levels of stem cell genes [101]. In addition, the increase in GRP78 value in gefitinib-resistant lung cancer cells is accompanied by an increase in the characteristics of epithelial-mesenchymal transition and cancer stem cells, and the decrease in resistance to gefitinib may be due to its reduction in GRP78 [102]. It can be seen that GRP78 imparts stemness to cancer cells by transmitting signals, which participates in the resistance of cells to treatment.

\section{Clinical significance of GRP78}

Since GRP78 is a key factor in multiple steps in tumor biology, GRP78 may have a significant clinical impact on lung cancer. First, GRP78 can be used as a target for tumor therapy. Secondly, the expression of UPR-related proteins, especially GRP78, can improve the therapeutic effect of drugs commonly used in the clinic. Finally, GRP78 can be used as a biomarker for the prognosis and evaluation of lung cancer patients.

\section{GRP78 can be used as a target for lung cancer treatment} Considering the importance of GRP78 in cancer cell survival, it is a prime target for anticancer drugs (Table 1). Interestingly, several naturally occurring compounds are thought to have anticancer activities that can inhibit the expression or activity of GRP78. Epigallocatechin gallate

Table 1 GRP78-targeted drug therapies for cancer treatment

\begin{tabular}{|c|c|c|}
\hline Drugs & Effects & Study \\
\hline Versipelostatin & Inhibits transcription factors & Colon and stomach cancer [105] \\
\hline EGCG & Binds to ATP binding domain and alters ATPase activity & Breast cancer [103] \\
\hline Subtilase cytotoxin (AB5) & GRP78 proteolytic cleavage & Lung cancer [104] \\
\hline GIRLRG & Targets cell surface GRP78 & $\begin{array}{l}\text { Lung cancer [119], } \\
\text { glioma, and breast cancer [117] }\end{array}$ \\
\hline CTVALPGGYVRVC & & Melanoma [114] \\
\hline WIFPWIQL & & Prostate and breast cancer [116] \\
\hline Bag-1 peptide & & Prostate cancer [118] \\
\hline Antibody & & Lung cancer and glioblastoma [113] \\
\hline Kringle 5 (K5) & & Fibrosarcoma [111] \\
\hline
\end{tabular}


(EGCG) can bind to the ATPase domain of GRP78 and inhibit its catalytic activity [103]. In addition, several cytotoxins have been shown to inhibit GRP78 activity by direct lysis. For example, the bacterial AB5 subtilase cytotoxin (subAB) can specifically lyse GRP78 on a single amino acid, making it possible to use it for anticancer therapy [104]. In addition, the GRP78-targeted subtilase cytotoxin catalytic subunit is fused with epidermal growth factor (EGF-SubA) to make a variety of cancer cells sensitive to photodynamic therapy (PDT), including human squamous cell lung cancer SW-900. Hence, PDT and EGF-SubA can more effectively kill cancer cells when used in combination [97]. Versipelostatin inhibits the transcription of GRP78 target genes and initiates UPRinduced apoptosis under glucose deprivation $[105,106]$. The macrocyclic compound also destroys certain components of the UPR and selectively kills glucose-deficient cancer cells. It can also inhibit tumor growth in xenografts when used in conjunction with cisplatin. GRP78 and related subtypes can be detected in the nucleus, mitochondria, cytoplasm, and ER of lung cancer cells [40, 107, 108]. GRP78 can also translocate to the cell surface [109], where it can act as a receptor for multiple signal transduction pathways, thereby amplifying its biological effects [110]. This provides an exciting opportunity to target cell surface GRP78 for developing new anticancer therapies. The kringle 5 domain (K5) of the human plasminogen can bind to GRP78 on the surface of endothelial cells and tumor cells and induce apoptosis [111, 112]. Targeted cell surface GRP78 antibodies slow the proliferation and colony formation of NSCLC cells and promote their apoptosis in vitro and in vivo. Yet, the antibody does not reduce the function of normal lung cells [113]. Tumor-targeting peptides are also promising drugs for tumor-targeting therapy. Several peptides have been clearly identified that bind to GRP78 on the surface of tumor cells [114-118], including lung cancer cells [119]. This finding can be used to target tumors and develop new targeted drugs for clinical and scientific research.

\section{ER stress and cancer cell sensitivity to therapy}

Many research studies have indicated that the combination of existing chemotherapy drugs and UPR inhibitors or activators can prevents cell protection and induce cellular apoptosis, reinstate the sensitivity of cancer cells to chemotherapy drugs, and improve the efficacy of chemotherapy drugs with unclear molecular mechanisms. Inducing UPR signaling makes NSCLC cells sensitive to doxorubicin, at least partly through inactivation of the mTOR signaling pathway, which is mediated by eIF $2 \alpha$ [120]. The targeted GRP78 antibody can inhibit the PIK3/ AKT/mTOR signaling pathway and increase the radiosensitivity of NSCLC cells [113]. Currently, cisplatin is used in combination with other therapies in the clinic $[121,122]$. Therefore, there is an urgent need to develop new strategies to reduce cisplatin-induced resistance in tumor cells while also reducing the common side effects of cisplatin-based treatment regimens [123]. The inhibition of glutamine fructose-6-phosphate aminotransferase (GFAT) activity downregulates the expression of GRP78 and activated IRE $1 \alpha$, a sensitive protein in response to unfolded proteins, thereby promoting cisplatin-induced apoptosis in NSCLC cells [124]. In addition, 4-PBA, which is an ER stress antagonist, enhances the sensitivity of human lung adenocarcinoma cells to DMAS [23]. However, the ER stress inducer THA sensitizes lung adenocarcinoma cells to icariin treatment [125]. Autophagy inhibitors significantly enhance the cytotoxicity of erlotinib to tyrosine kinase inhibitor (TKI)-resistant lung cancer cells through ER stress-induced apoptosis [126].

In view of the effects of oxidative stress on cell apoptosis and treatment, regulating oxidative stress and ER stress may be beneficial to the sensitivity of lung cancer to treatment. PDT produces high-cytotoxic ROS, especially singlet oxygen $\left({ }^{1} \mathrm{O}_{2}\right)$, which kills tumor cells through apoptosis/necrosis, while protecting normal tissues. However, the ER stress caused by PDT causes cells to initiate UPR to restore protein homeostasis and normalize ER function, and then cells can survive under this cytoprotective mechanism, which greatly reduces the efficacy of PDT [127]. Therefore, the combined use of drugs that target GRP78 destroys this protective mechanism, facilitates the accumulation of ROS in cells, and increases the sensitivity of lung cancer cells to PDT [97].

\section{GRP78 as a biomarker for early diagnosis, staging and prognosis of lung cancer}

Due to the difficulties in diagnosing lung cancer, many patients present with advanced-stage disease at this initial assessment, which can lead to poorer prognoses [128-130]. Therefore, more information is needed to determine the prognosis of these patients. Molecular diagnostics can provide an objective and systematic classification of human cancers. However, researchers have been unable to identify any prognostic markers of lung cancer. GRP78 is highly enriched in the serum samples of patients with advanced-stage NSCLC. Compared with patients with lower GRP78 expression, patients with higher GRP78 expression have a shorter survival time (median overall survival, 39 months vs. 49 months). Hence, high GRP78 expression may indicate a shorter overall survival period [131]. Compared with the paired normal tissues of the same patient, the expression of genes and protein levels in cancer tissues was increased. In addition, GRP78 overexpression in cancer tissues is related to the degree and stage of tumor differentiation. 
GRP78 expression in poorly differentiated tumors is stronger than that in highly differentiated tumors, and the expression of stage III tumors is also stronger than that of stage I and II and tumors [7]. GRP78 can also be used as a prognostic indicator for predicting the response of patients to chemotherapy. For example, the rs430397 AA genotype in GRP78 is associated with reduced survival and higher recurrence in patients with advancedstage NSCLC who receive platinum chemotherapy [132]. Therefore, GRP78 can be considered as a potential marker for evaluating the prognosis of lung cancer patients.

\section{Conclusion and outlook}

The role of GRP78 in the growth, progression, and outcomes of lung cancer is becoming increasingly evident. GRP78 is the main regulatory protein of UPR, affecting both tumor cells and the tumor microenvironment. When changes in the microenvironment are felt, such as inflammation, hypoxia, nutritional deficiencies, and acidosis, GRP78 becomes overexpressed and migrates to the surface of tumor cells, leading to a series of cancer features.

Cell survival and death are heavily controlled by apoptosis and autophagy. The interaction between autophagy and apoptosis affects the stability of the intracellular environment, the clearance of dead cells, and clinical treatment. GRP78 has a dual role in the regulation of autophagy and apoptosis in lung cancer, and is highly dependent on the cell type and stimulation conditions. In some cases, autophagy has a protective effect on lung cancer cell apoptosis, while in other instances, autophagy and apoptosis have a synergistic effect. In general, mild ER stress can induce autophagy, promote the balance of the intracellular environment, and inhibit apoptosis. However, sustained and robust ER stress will induce apoptosis. Therefore, it is essential to know the factors that affect the balance between UPR-mediated survival and death responses. Since malignancies continually activate UPR in response to environmental stress, they may have also formed mechanisms to avoid UPR-induced apoptosis.

On the one hand, GRP78 overexpression in lung cancer cells may increase the secretion of GRP78, stimulate the formation of non-malignant stromal cells, and thereby support tumor growth. On the other hand, GRP78 overexpression induces EMT in lung cancer cells, contributing to the metastatic potential of lung cancer cells. Currently, there is a limited number of studies on the role of GRP78 in the tumor microenvironment. Therefore, it is necessary to conduct research in patient-derived cell culture models to further assess the role of GRP78, its involved UPR branch, and its downstream effects in the occurrence and progression of lung cancer. The increased GRP78 activity levels in lung cancer specimens may indicate that lung cancer cells may be able to overcome the harsh tumor microenvironment through adaptive mechanisms.

Since GRP78 may be the main factor in the occurrence of lung cancer, GRP78 can be used as a biomarker for the early diagnosis of lung cancer, or combined with existing biomarkers to improve the specificity and sensitivity of the lung cancer diagnosis. At present, some studies have shown that GRP78 can be used as a biomarker to evaluate the prognosis of lung cancer patients. Hence, the expression of GRP78 in the sera samples of lung cancer patients may be used to evaluate the response to treatment and predict the prognosis of lung cancer patients in the clinic. This may improve the accuracy of evaluation and treatment. In addition, lung cancer often resists existing treatment methods, leading to the enrichment of drug-resistant tumor cell subgroups, cancer recurrence, and ultimately patient death. GRP78 may be the primary factor for the development of drug resistance in lung cancer, as its specific inhibitors and targeted agents have excellent therapeutic prospects. Furthermore, GRP78mediated ER stress can enhance the sensitivity of lung cancer cells to chemotherapy, so combined GRP78-based therapies should also be considered. Accurate cancer imaging is essential for the evaluation of patients before, during, and after treatment. Using this biomarker, the development of targeted imaging for lung cancer can be considered to specifically detect all cancer cells within a heterogeneous tumor while keeping normal cells intact. Since GRP78 plays a broad role in inflammation, novel GRP78-related immunotherapies could be developed in future.

In addition, how does GRP78 regulate lung cancer in multiple intracellular locations? Does GRP78 play a regulatory role in lung cancer-specific metastasis? What is the relationship between GRP78 and lung cancer metabolism? We recommend the establishment of a specific conditional knockout model of GRP78 in different parts of the cell and a model of lung cancer-specific metastasis, which will help to further reveal the function and regulatory effects of GRP78 in lung cancer. Our increased knowledge of these mechanisms may aid in the discovery of other tumor cell weaknesses, which can be translated into the development of novel treatment strategies in the future.

\footnotetext{
Abbreviations

GRP78: Glucose-regulating protein 78; ER: Endoplasmic reticulum; UPR: Unfolded protein response; BiP: Binding protein; IRE1: Inositol-requiring enzyme 1; PERK: PRKR-like ER kinase; ATF6: Activating transcription factor 6; RNase: Ribonuclease; XBP1: X-box binding protein; ERAD: ER-related protein degradation; JNK: C-jun n-terminal kinase; TNF: Tumor necrosis factor; TRAF2:
} 
Tumor necrosis factor receptor-related factor 2; elF2: Eukaryotic translation initiation factor 2a; ATF4: Activating transcription factor 4; CHOP: CCAAT/ enhancer-binding protein-homologous protein; NRF2: Nuclear factor erythroid 2-related factor 2; SiP1: Site-1-protease; SiP2: Site-2-protease; bZIP: Basic leucine zipper; ROS: Reactive oxygen species; COPD: Chronic obstructive pulmonary disease; DMAS: $\beta, \beta$-Dimethylacrylshikonin; HOCl: Hypochlorous acid; EMT: Epithelial-mesenchymal transition; CAFs: Cancer-associated fibroblasts; GALNT6: Polypeptide N-acetylgalactosaminyltransferase-6; PDT: Photodynamic therapy; GFAT: Glutamine fructose-6-phosphate aminotransferase; TKI: Tyrosine kinase inhibitor.

\section{Acknowledgements}

Not applicable.

\section{Authors' contributions}

SX and WD designed the review, organized the document and wrote the manuscript together. WL, XZ and QW conceived and supervised the review, and revised the manuscript. All authors read and approved the final manuscript.

\section{Funding}

This work was funded by the National Natural Science Foundation of China (No. 81972916).

\section{Availability of data and materials}

Not applicable.

\section{Declarations}

Ethics approval and consent to participate

Not applicable.

\section{Consent for publication}

Not applicable.

\section{Competing interests}

The authors declare that they have no competing interests.

\section{Author details}

${ }^{1}$ Department of Respiratory Medicine, The Second Hospital, Dalian Medical University, No. 467 Zhongshan Road, Dalian 116023, China. ${ }^{2}$ Cancer Translational Medicine Research Center, The Second Hospital, Dalian Medical University, Dalian 116023, China. ${ }^{3}$ Department of Respiratory and Critical Care Medicine, The First Hospital, Shanxi Medical University, No. 85 Jiefang South Road, Taiyuan 030001, Shanxi, China.

Received: 20 December 2020 Accepted: 13 March 2021

Published online: 21 March 2021

\section{References}

1. Siegel RL, Miller KD, Jemal A. Cancer statistics, 2016. CA Cancer J Clin. 2016;66:7-30

2. Barta JA, Powell CA, Wisnivesky JP. Global epidemiology of lung cancer. Ann Glob Health. 2019;85:8.

3. Siegel RL, Miller KD, Jemal A. Cancer statistics, 2020. CA Cancer J Clin. 2020;70:7-30

4. Lee AS. The glucose-regulated proteins: stress induction and clinical applications. Trends Biochem Sci. 2001;26:504-10.

5. Li X, Zhang K, Li Z. Unfolded protein response in cancer: the physician's perspective. J Hematol Oncol. 2011;4:8

6. Chang P, Zhang X, Zhang M, Li G, Hu L, Zhao H, Zhu X, Wu J, Wang X, Wang $K$, et al. Swimming exercise inhibits myocardial ER stress in the hearts of aged mice by enhancing CGMPPKG signaling. Mol Med Rep. 2020;21:549-56.

7. Wang Q, He Z, Zhang J, Wang Y, Wang T, Tong S, Wang L, Wang S, Chen $Y$. Overexpression of endoplasmic reticulum molecular chaperone
GRP94 and GRP78 in human lung cancer tissues and its significance. Cancer Detect Prev. 2005;29:544-51.

8. Uramoto H, Sugio K, Oyama T, Nakata S, Ono K, Yoshimastu T, Morita M, Yasumoto K. Expression of endoplasmic reticulum molecular chaperone Grp78 in human lung cancer and its clinical significance. Lung Cancer. 2005;49:55-62.

9. Munro S, Pelham HR. An Hsp70-like protein in the ER: identity with the $78 \mathrm{kd}$ glucose-regulated protein and immunoglobulin heavy chain binding protein. Cell. 1986:46:291-300.

10. Lee AS. Mammalian stress response: induction of the glucose-regulated protein family. Curr Opin Cell Biol. 1992;4:267-73.

11. Almen MS, Nordstrom KJ, Fredriksson R, Schioth HB. Mapping the human membrane proteome: a majority of the human membrane proteins can be classified according to function and evolutionary origin. BMC Biol. 2009;7:50

12. Diehl JA, Fuchs SY, Koumenis C. The cell biology of the unfolded protein response. Gastroenterology. 2011;141:38-41.

13. Sano R, Reed JC. ER stress-induced cell death mechanisms. Biochim Biophys Acta. 2013;1833:3460-70.

14. Tsai YC, Weissman AM. The unfolded protein response, degradation from endoplasmic reticulum and cancer. Genes Cancer. 2010;1:764-78.

15. Prischi F, Nowak PR, Carrara M, Ali MM. Phosphoregulation of Ire1 RNase splicing activity. Nat Commun. 2014;5:3554.

16. Kondratyev M, Avezov E, Shenkman M, Groisman B, Lederkremer GZ. PERK-dependent compartmentalization of ERAD and unfolded protein response machineries during ER stress. Exp Cell Res. 2007:313:3395-407.

17. Tam AB, Koong AC, Niwa M. Ire1 has distinct catalytic mechanisms for XBP1/HAC1 splicing and RIDD. Cell Rep. 2014;9:850-8.

18. Hollien J, Lin JH, Li H, Stevens N, Walter P, Weissman JS. Regulated Ire 1dependent decay of messenger RNAs in mammalian cells. J Cell Biol. 2009;186:323-31.

19. Urano F, Wang X, Bertolotti A, Zhang Y, Chung P, Harding HP, Ron D. Coupling of stress in the ER to activation of JNK protein kinases by transmembrane protein kinase IRE1. Science. 2000;287:664-6.

20. Rzymski T, Milani M, Singleton DC, Harris AL. Role of ATF4 in regulation of autophagy and resistance to drugs and hypoxia. Cell Cycle. 2009:8:3838-47.

21. Wu J, Kaufman RJ. From acute ER stress to physiological roles of the unfolded protein response. Cell Death Differ. 2006:13:374-84.

22. Hetz C, Chevet E, Harding HP. Targeting the unfolded protein response in disease. Nat Rev Drug Discov. 2013:12:703-19.

23. Wang $H$, Zhang G. Endoplasmic reticulum stress-mediated autophagy protects against beta, beta-dimethylacrylshikonin-induced apoptosis in lung adenocarcinoma cells. Cancer Sci. 2018;109:1889-901.

24. Brem GJ, Mylonas I, Bruning A. Eeyarestatin causes cervical cancer cell sensitization to bortezomib treatment by augmenting ER stress and CHOP expression. Gynecol Oncol. 2013;128:383-90.

25. Cullinan SB, Diehl JA. Coordination of ER and oxidative stress signaling: the PERK/Nrf2 signaling pathway. Int J Biochem Cell Biol. 2006;38:317-32.

26. Shen J, Chen X, Hendershot L, Prywes R. ER stress regulation of ATF6 localization by dissociation of BiP/GRP78 binding and unmasking of Golgi localization signals. Dev Cell. 2002;3:99-111.

27. Teske BF, Wek SA, Bunpo P, Cundiff JK, McClintick JN, Anthony TG, Wek RC. The elF2 kinase PERK and the integrated stress response facilitate activation of ATF6 during endoplasmic reticulum stress. Mol Biol Cell. 2011;22:4390-405.

28. Hetz C. The unfolded protein response: controlling cell fate decisions under ER stress and beyond. Nat Rev Mol Cell Biol. 2012;13:89-102.

29. Kim KM, Yu TK, Chu HH, Park HS, Jang KY, Moon WS, Kang MJ, Lee DG, Kim MH, Lee JH, Chung MJ. Expression of ER stress and autophagyrelated molecules in human non-small cell lung cancer and premalignant lesions. Int J Cancer. 2012:131:E362-370.

30. Kenche H, Baty CJ, Vedagiri K, Shapiro SD, Blumental-Perry A. Cigarette smoking affects oxidative protein folding in endoplasmic reticulum by modifying protein disulfide isomerase. FASEB J. 2013;27:965-77.

31. Dauer P, Sharma NS, Gupta VK, Durden B, Hadad R, Banerjee S, Dudeja $V$, Saluja A, Banerjee S. ER stress sensor, glucose regulatory protein 78 (GRP78) regulates redox status in pancreatic cancer thereby maintaining "stemness." Cell Death Dis. 2019;10:132. 
32. Wei PC, Hsieh YH, Su MI, Jiang X, Hsu PH, Lo WT, Weng JY, Jeng YM, Wang JM, Chen PL, et al. Loss of the oxidative stress sensor NPGPX compromises GRP78 chaperone activity and induces systemic disease. Mol Cell. 2012;48:747-59.

33. Zhang Q, Ganapathy S, Avraham H, Nishioka T, Chen C. Nicotine exposure potentiates lung tumorigenesis by perturbing cellular surveillance. Br J Cancer. 2020;122:904-11.

34. Li E, Xu Z, Liu F, Wang H, Wen J, Shao S, Zhang L, Wang L, Liu C, Lu J, et al. Continual exposure to cigarette smoke extracts induces tumorlike transformation of human nontumor bronchial epithelial cells in a microfluidic chip. J Thorac Oncol. 2014;9:1091-100.

35. Tsai HY, Yang YF, Wu AT, Yang CJ, Liu YP, Jan YH, Lee CH, Hsiao YW, Yeh $\mathrm{CT}$, Shen $\mathrm{CN}$, et al. Endoplasmic reticulum ribosome-binding protein 1 (RRBP1) overexpression is frequently found in lung cancer patients and alleviates intracellular stress-induced apoptosis through the enhancement of GRP78. Oncogene. 2013;32:4921-31.

36. Du T, Li H, Fan Y, Yuan L, Guo X, Zhu Q, Yao Y, Li X, Liu C, Yu X, et al. The deubiquitylase OTUD3 stabilizes GRP78 and promotes lung tumorigenesis. Nat Commun. 2019;10:2914.

37. Lee AS. Glucose-regulated proteins in cancer: molecular mechanisms and therapeutic potential. Nat Rev Cancer. 2014;14:263-76.

38. Lee AS. GRP78 induction in cancer: therapeutic and prognostic implications. Cancer Res. 2007;67:3496-9.

39. Shu CW, Sun FC, Cho JH, Lin CC, Liu PF, Chen PY, Chang MD, Fu HW, Lai YK. GRP78 and Raf-1 cooperatively confer resistance to endoplasmic reticulum stress-induced apoptosis. J Cell Physiol. 2008;215:627-35.

40. Reddy RK, Mao C, Baumeister P, Austin RC, Kaufman RJ, Lee AS. Endoplasmic reticulum chaperone protein GRP78 protects cells from apoptosis induced by topoisomerase inhibitors: role of ATP binding site in suppression of caspase-7 activation. J Biol Chem. 2003;278:20915-24.

41. Yang J, Chen H, Wang Q, Deng S, Huang M, Ma X, Song P, Du J, Huang $Y$, Wen $Y$, et al. Inhibitory effect of kurarinone on growth of human nonsmall cell lung cancer: an experimental study both in vitro and in vivo studies. Front Pharmacol. 2018;9:252.

42. Xie L, Chen Y, Chen J, Zhang H, Liao Y, Zhou Y, Zhou L, Qing C. Antitumor effects and mechanism of GA-13315, a novel gibberellin derivative, in human lung adenocarcinoma: an in vitro and in vivo study. Cell Mol Biol Lett. 2019;24:6.

43. Ning J, Lin Z, Zhao X, Zhao B, Miao J. Inhibiting lysine 353 oxidation of GRP78 by a hypochlorous probe targeting endoplasmic reticulum promotes autophagy in cancer cells. Cell Death Dis. 2019;10:858.

44. Hsia TC, Yang JS, Chen GW, Chiu TH, Lu HF, Yang MD, Yu FS, Liu KC, Lai KC, Lin CC, Chung JG. The roles of endoplasmic reticulum stress and $\mathrm{Ca} 2+$ on rhein-induced apoptosis in A-549 human lung cancer cells. Anticancer Res. 2009;29:309-18.

45. Wang $X$, Chen C, Zhou G, Ye J, Yin R, Feng D, Zhang S, Wang X, Zhao X, Zhang Z. Sepia ink oligopeptide induces apoptosis of lung cancer cells via mitochondrial pathway. Cell Physiol Biochem. 2018;45:2095-106.

46. Kim I, Xu W, Reed JC. Cell death and endoplasmic reticulum stress: disease relevance and therapeutic opportunities. Nat Rev Drug Discov. 2008;7:1013-30.

47. Ghosh R, Wang L, Wang ES, Perera BG, Igbaria A, Morita S, Prado K, Thamsen M, Caswell D, Macias H, et al. Allosteric inhibition of the IRE1 alpha RNase preserves cell viability and function during endoplasmic reticulum stress. Cell. 2014;158:534-48

48. Zhang J, Liang Y, Lin Y, Liu Y. YouYou, Yin W: IRE1 alpha-TRAF2-ASK1 pathway is involved in CSTMP-induced apoptosis and ER stress in human non-small cell lung cancer A549 cells. Biomed Pharmacother. 2016;82:281-9.

49. Zhao Y, Zhu C, Li X, Zhang Z, Yuan Y, Ni Y, Liu T, Deng S, Zhao J, Wang Y. Asterosaponin 1 induces endoplasmic reticulum stress-associated apoptosis in A549 human lung cancer cells. Oncol Rep. 2011;26:919-24.

50. Tabas I, Ron D. Integrating the mechanisms of apoptosis induced by endoplasmic reticulum stress. Nat Cell Biol. 2011;13:184-90.

51. Gu S, Yang $X C$, Xiang $X Y$, W $Y$ Y, Zhang $Y$, Yan $X Y$, Xue YN, Sun LK, Shao GG. Sanguinarine-induced apoptosis in lung adenocarcinoma cells is dependent on reactive oxygen species production and endoplasmic reticulum stress. Oncol Rep. 2015;34:913-9.

52. Dogra N, Mukhopadhyay T. Impairment of the ubiquitin-proteasome pathway by methyl $\mathrm{N}$-(6-phenylsulfanyl-1H-benzimidazol-2-yl) carbamate leads to a potent cytotoxic effect in tumor cells: a novel antiproliferative agent with a potential therapeutic implication. J Biol Chem. 2012;287:30625-40.

53. Hurley JH, Schulman BA. Atomistic autophagy: the structures of cellular self-digestion. Cell. 2014;157:300-11.

54. Liu G, Pei F, Yang F, Li L, Amin AD, Liu S, Buchan JR, Cho WC. Role of autophagy and apoptosis in non-small-cell lung cancer. Int J Mol Sci. 2017;18:367.

55. Zhang M, Su L, Xiao Z, Liu X, Liu X. Methyl jasmonate induces apoptosis and pro-apoptotic autophagy via the ROS pathway in human nonsmall cell lung cancer. Am J Cancer Res. 2016;6:187-99.

56. Bernales S, McDonald KL, Walter P. Autophagy counterbalances endoplasmic reticulum expansion during the unfolded protein response. PLoS Biol. 2006:4:e423.

57. Yorimitsu T, Nair U, Yang Z, Klionsky DJ. Endoplasmic reticulum stress triggers autophagy. J Biol Chem. 2006;281:30299-304.

58. Ogata M, Hino S, Saito A, Morikawa K, Kondo S, Kanemoto S, Murakami T, Taniguchi M, Tanii I, Yoshinaga K, et al. Autophagy is activated for cell survival after endoplasmic reticulum stress. Mol Cell Biol. 2006;26:9220-31.

59. Strohecker AM, Guo JY, Karsli-Uzunbas G, Price SM, Chen GJ, Mathew R, McMahon M, White E. Autophagy sustains mitochondrial glutamine metabolism and growth of BrafV600E-driven lung tumors. Cancer Discov. 2013;3:1272-85.

60. Karsli-Uzunbas G, Guo JY, Price S, Teng X, Laddha SV, Khor S, Kalaany NY, Jacks T, Chan CS, Rabinowitz JD, White E. Autophagy is required for glucose homeostasis and lung tumor maintenance. Cancer Discov. 2014:4:914-27.

61. Cook KL, Shajahan AN, Warri A, Jin L, Hilakivi-Clarke LA, Clarke R. Glucose-regulated protein 78 controls cross-talk between apoptosis and autophagy to determine antiestrogen responsiveness. Cancer Res. 2012;72:3337-49.

62. Pyrko P, Schonthal AH, Hofman FM, Chen TC, Lee AS. The unfolded protein response regulator GRP78/BiP as a novel target for increasing chemosensitivity in malignant gliomas. Cancer Res. 2007;67:9809-16.

63. Xie WY, Zhou XD, Li Q, Chen LX, Ran DH. Acid-induced autophagy protects human lung cancer cells from apoptosis by activating ER stress. Exp Cell Res. 2015;339:270-9.

64. Shimodaira Y, Takahashi S, Kinouchi Y, Endo K, Shiga H, Kakuta Y, Kuroha M, Shimosegawa T. Modulation of endoplasmic reticulum (ER) stressinduced autophagy by C/EBP homologous protein (CHOP) and inositolrequiring enzyme 1alpha (IRE1alpha) in human colon cancer cells. Biochem Biophys Res Commun. 2014;445:524-33.

65. Gan PP, Zhou YY, Zhong MZ, Peng Y, Li L, Li JH. Endoplasmic reticulum stress promotes autophagy and apoptosis and reduces chemotherapy resistance in mutant p53 lung cancer cells. Cell Physiol Biochem. 2017:44:133-51.

66. Jarauta V, Jaime P, Gonzalo O, de Miguel D, Ramirez-Labrada A, Martinez-Lostao L, Anel A, Pardo J, Marzo I, Naval J. Inhibition of autophagy with chloroquine potentiates carfilzomib-induced apoptosis in myeloma cells in vitro and in vivo. Cancer Lett. 2016;382:1-10.

67. Salazar M, Carracedo A, Salanueva IJ, Hernandez-Tiedra S, Lorente M, Egia A, Vazquez P, Blazquez C, Torres S, Garcia S, et al. Cannabinoid action induces autophagy-mediated cell death through stimulation of ER stress in human glioma cells. J Clin Invest. 2009;119:1359-72.

68. Sun Q, Hua J, Wang Q, Xu W, Zhang J, Zhang J, Kang J, Li M. Expressions of GRP78 and Bax associate with differentiation, metastasis, and apoptosis in non-small cell lung cancer. Mol Biol Rep. 2012;39:6753-61.

69. Jamora C, Dennert G, Lee AS. Inhibition of tumor progression by suppression of stress protein GRP78/BiP induction in fibrosarcoma B/ C10ME. Proc Natl Acad Sci USA. 1996;93:7690-4.

70. Chang YJ, Chen WY, Huang CY, Liu HH, Wei PL. Glucose-regulated protein 78 (GRP78) regulates colon cancer metastasis through EMT biomarkers and the NRF-2/HO-1 pathway. Tumour Biol. 2015;36:1859-69.

71. Zhao G, Kang J, Jiao K, Xu G, Yang L, Tang S, Zhang H, Wang Y, Nie Y, Wu $\mathrm{K}$, et al. High expression of GRP78 promotes invasion and metastases in patients with esophageal squamous cell carcinoma. Dig Dis Sci. 2015;60:2690-9.

72. Teng Y, Ren X, Li H, Shull A, Kim J, Cowell JK. Mitochondrial ATAD3A combines with GRP78 to regulate the WASF3 metastasis-promoting protein. Oncogene. 2016;35:333-43. 
73. Zhang XX, Li HD, Zhao S, Zhao L, Song HJ, Wang G, Guo QJ, Luan ZD, Su RJ. The cell surface GRP78 facilitates the invasion of hepatocellular carcinoma cells. Biomed Res Int. 2013;2013:917296.

74. Li Z, Zhang L, Zhao Y, Li H, Xiao H, Fu R, Zhao C, Wu H, Li Z. Cell-surface GRP78 facilitates colorectal cancer cell migration and invasion. Int J Biochem Cell Biol. 2013;45:987-94.

75. Fu Y, Lee AS. Glucose regulated proteins in cancer progression, drug resistance and immunotherapy. Cancer Biol Ther. 2006;5:741-4.

76. Chiu CC, Lin CY, Lee LY, Chen YJ, Kuo TF, Chang JT, Liao CT, Wang HM, Yen TC, Shen CR, et al. Glucose-regulated protein 78 regulates multiple malignant phenotypes in head and neck cancer and may serve as a molecular target of therapeutic intervention. Mol Cancer Ther. 2008;7:2788-97.

77. Vaupel P, Kallinowski F, Okunieff P. Blood flow, oxygen and nutrient supply, and metabolic microenvironment of human tumors: a review. Cancer Res. 1989:49:6449-65.

78. Yanagisawa K, Konishi H, Arima C, Tomida S, Takeuchi T, Shimada Y, Yatabe Y, Mitsudomi T, Osada H, Takahashi T. Novel metastasis-related gene CIM functions in the regulation of multiple cellular stress-response pathways. Cancer Res. 2010;70:9949-58.

79. Koomagi R, Mattern J, Volm M. Glucose-related protein (GRP78) and its relationship to the drug-resistance proteins P170, GST-pi, LRP56 and angiogenesis in non-small cell lung carcinomas. Anticancer Res. 1999:19:4333-6.

80. Dong D, Ni M, Li J, Xiong S, Ye W, Virrey JJ, Mao C, Ye R, Wang M, Pen L, et al. Critical role of the stress chaperone GRP78/BiP in tumor proliferation, survival, and tumor angiogenesis in transgene-induced mammary tumor development. Cancer Res. 2008;68:498-505.

81. Dong D, Stapleton C, Luo B, Xiong S, Ye W, Zhang Y, Jhaveri N, Zhu G, Ye R, Liu Z, et al. A critical role for GRP78/BiP in the tumor microenvironment for neovascularization during tumor growth and metastasis. Cancer Res. 2011;71:2848-57.

82. Binet F, Sapieha P. ER Stress and Angiogenesis. Cell Metab. 2015;22:560-75

83. Drogat B, Auguste $P$, Nguyen DT, Bouchecareilh M, Pineau R, Nalbantoglu J, Kaufman RJ, Chevet E, Bikfalvi A, Moenner M. IRE1 signaling is essential for ischemia-induced vascular endothelial growth factor-A expression and contributes to angiogenesis and tumor growth in vivo. Cancer Res. 2007;67:6700-7.

84. Romero-Ramirez L, Cao H, Regalado MP, Kambham N, Siemann D, Kim $J$ J, Le QT, Koong AC. X box-binding protein 1 regulates angiogenesis in human pancreatic adenocarcinomas. Transl Oncol. 2009;2:31-8.

85. Shiga K, Hara M, Nagasaki T, Sato T, Takahashi H, Takeyama H. Cancerassociated fibroblasts: their characteristics and their Roles in tumor growth. Cancers (Basel). 2015;7:2443-58.

86. Liu T, Han C, Wang S, Fang P, Ma Z, Xu L, Yin R. Cancer-associated fibroblasts: an emerging target of anti-cancer immunotherapy. J Hematol Oncol. 2019;12:86

87. Peng Y, Li Z, Li Z. GRP78 secreted by tumor cells stimulates differentiation of bone marrow mesenchymal stem cells to cancer-associated fibroblasts. Biochem Biophys Res Commun. 2013:440:558-63.

88. Yu T, Guo Z, Fan H, Song J, Liu Y, Gao Z, Wang Q. Cancer-associated fibroblasts promote non-small cell lung cancer cell invasion by upregulation of glucose-regulated protein 78 (GRP78) expression in an integrated bionic microfluidic device. Oncotarget. 2016;7:25593-603.

89. Zhang L, Li Z, Fan Y, Li H, Li Z, Li Y. Overexpressed GRP78 affects EMT and cell-matrix adhesion via autocrine TGF-beta/Smad2/3 signaling. Int J Biochem Cell Biol. 2015;64:202-11.

90. Sun LL, Chen CM, Zhang J, Wang J, Yang CZ, Lin LZ. Glucose-regulated protein 78 signaling regulates hypoxia-induced epithelial-mesenchymal transition in A549 cells. Front Oncol. 2019;9:137.

91. Song J, Liu W, Wang J, Hao J, Wang Y, You X, Du X, Zhou Y, Ben J, Zhang $X$, et al. GALNT6 promotes invasion and metastasis of human lung adenocarcinoma cells through O-glycosylating chaperone protein GRP78. Cell Death Dis. 2020;11:352.

92. Holohan C, Van Schaeybroeck S, Longley DB, Johnston PG. Cancer drug resistance: an evolving paradigm. Nat Rev Cancer. 2013;13:714-26.

93. Dong D, Ko B, Baumeister P, Swenson S, Costa F, Markland F, Stiles C, Patterson JB, Bates SE, Lee AS. Vascular targeting and antiangiogenesis agents induce drug resistance effector GRP78 within the tumor microenvironment. Cancer Res. 2005:65:5785-91.
94. Wang J, Yin Y, Hua H, Li M, Luo T, Xu L, Wang R, Liu D, Zhang Y, Jiang Y. Blockade of GRP78 sensitizes breast cancer cells to microtubulesinterfering agents that induce the unfolded protein response. J Cell Mol Med. 2009;13:3888-97.

95. Kim JK, Kang KA, Piao MJ, Ryu YS, Han X, Fernando PM, Oh MC, Park $J$ J, Shilnikova K, Boo SJ, et al. Endoplasmic reticulum stress induces 5-fluorouracil resistance in human colon cancer cells. Environ Toxicol Pharmacol. 2016;44:128-33.

96. Chen D, Rauh M, Buchfelder M, Eyupoglu IY, Savaskan N. The oxidometabolic driver ATF4 enhances temozolamide chemo-resistance in human gliomas. Oncotarget. 2017;8:51164-76.

97. Firczuk M, Gabrysiak M, Barankiewicz J, Domagala A, Nowis D, Kujawa M, Jankowska-Steifer E, Wachowska M, Glodkowska-Mrowka E, Korsak $B$, et al. GRP78-targeting subtilase cytotoxin sensitizes cancer cells to photodynamic therapy. Cell Death Dis. 2013;4:e741.

98. Lin Y, Wang Z, Liu L, Chen L. Akt is the downstream target of GRP78 in mediating cisplatin resistance in ER stress-tolerant human lung cancer cells. Lung Cancer. 2011;71:291-7.

99. Dean M, Fojo T, Bates S. Tumour stem cells and drug resistance. Nat Rev Cancer. 2005;5:275-84.

100. Klauzinska M, Castro NP, Rangel MC, Spike BT, Gray PC, Bertolette D, Cuttitta F, Salomon D. The multifaceted role of the embryonic gene Cripto-1 in cancer, stem cells and epithelial-mesenchymal transition. Semin Cancer Biol. 2014;29:51-8.

101. Conner C, Lager TW, Guldner IH, Wu MZ, Hishida Y, Hishida T, Ruiz S, Yamasaki AE, Gilson RC, Belmonte JCl, et al. Cell surface GRP78 promotes stemness in normal and neoplastic cells. Sci Rep. 2020;10:3474

102. Liao CH, Tzeng YT, Lai GM, Chang CL, Hu MH, Tsai WL, Liu YR, Hsia S, Chuang SE, Chiou TJ, et al. Omega-3 fatty acid-enriched fish oil and selenium combination modulates endoplasmic reticulum stress response elements and reverses acquired gefitinib resistance in HCC827 lung adenocarcinoma cells. Mar Drugs. 2020;18:399.

103. Ermakova SP, Kang BS, Choi BY, Choi HS, Schuster TF, Ma WY, Bode AM, Dong Z. (-)-Epigallocatechin gallate overcomes resistance to etoposideinduced cell death by targeting the molecular chaperone glucoseregulated protein 78. Cancer Res. 2006;66:9260-9.

104. Paton AW, Beddoe T, Thorpe CM, Whisstock JC, Wilce MC, Rossjohn J, Talbot UM, Paton JC. AB5 subtilase cytotoxin inactivates the endoplasmic reticulum chaperone BiP. Nature. 2006;443:548-52.

105. Park HR, Tomida A, Sato S, Tsukumo Y, Yun J, Yamori T, Hayakawa Y, Tsuruo T, Shin-ya K. Effect on tumor cells of blocking survival response to glucose deprivation. J Natl Cancer Inst. 2004;96:1300-10.

106. Sasaki S, Samejima S, Uruga T, Anzai K, Nishi N, Kawakita E, Takao K, Tadano K. Synthetic studies of the spirocyclic cyclohexene part of versipelostatin, a novel GRP78/Bip molecular chaperone downregulator. J Antibiot (Tokyo). 2013;66:147-54.

107. Ni M, Zhou H, Wey S, Baumeister P, Lee AS. Regulation of PERK signaling and leukemic cell survival by a novel cytosolic isoform of the UPR regulator GRP78/BiP. PLoS ONE. 2009:4:e6868.

108. Sun FC, Wei S, Li CW, Chang YS, Chao CC, Lai YK. Localization of GRP78 to mitochondria under the unfolded protein response. Biochem J. 2006;396:31-9.

109. Zhang Y, Liu R, Ni M, Gill P, Lee AS. Cell surface relocalization of the endoplasmic reticulum chaperone and unfolded protein response regulator GRP78/BiP. J Biol Chem. 2010;285:15065-75.

110. Ni M, Zhang Y, Lee AS. Beyond the endoplasmic reticulum: atypical GRP78 in cell viability, signalling and therapeutic targeting. Biochem J. 2011:434:181-8.

111. Davidson DJ, Haskell C, Majest S, Kherzai A, Egan DA, Walter KA, Schneider A, Gubbins EF, Solomon L, Chen Z, et al. Kringle 5 of human plasminogen induces apoptosis of endothelial and tumor cells through surface-expressed glucose-regulated protein 78. Cancer Res. 2005;65:4663-72.

112. McFarland BC, Stewart J Jr, Hamza A, Nordal R, Davidson DJ, Henkin J, Gladson CL. Plasminogen kringle 5 induces apoptosis of brain microvessel endothelial cells: sensitization by radiation and requirement for GRP78 and LRP1. Cancer Res. 2009;69:5537-45.

113. Dadey DYA, Kapoor V, Hoye K, Khudanyan A, Collins A, Thotala D, Hallahan DE. Antibody targeting GRP78 enhances the efficacy of radiation therapy in human glioblastoma and non-small cell lung cancer cell lines and tumor models. Clin Cancer Res. 2017:23:2556-64. 
114. Kim Y, Lillo AM, Steiniger SC, Liu Y, Ballatore C, Anichini A, Mortarini R, Kaufmann GF, Zhou B, Felding-Habermann B, Janda KD. Targeting heat shock proteins on cancer cells: selection, characterization, and cell-penetrating properties of a peptidic GRP78 ligand. Biochemistry. 2006:45:9434-44

115. Yoneda Y, Steiniger SC, Capkova K, Mee JM, Liu Y, Kaufmann GF, Janda KD. A cell-penetrating peptidic GRP78 ligand for tumor cell-specific prodrug therapy. Bioorg Med Chem Lett. 2008;18:1632-6.

116. Arap MA, Lahdenranta J, Mintz PJ, Hajitou A, Sarkis AS, Arap W, Pasqualini R. Cell surface expression of the stress response chaperone GRP78 enables tumor targeting by circulating ligands. Cancer Cell. 2004;6:275-84.

117. Passarella RJ, Spratt DE, van der Ende AE, Phillips JG, Wu H, Sathiyakumar V, Zhou L, Hallahan DE, Harth E, Diaz R. Targeted nanoparticles that deliver a sustained, specific release of Paclitaxel to irradiated tumors. Cancer Res. 2010;70:4550-9.

118. Maddalo D, Neeb A, Jehle K, Schmitz K, Muhle-Goll C, Shatkina L, Walther TV, Bruchmann A, Gopal SM, Wenzel W, et al. A peptidic unconjugated GRP78/BiP ligand modulates the unfolded protein response and induces prostate cancer cell death. PLoS ONE. 2012;7:e45690.

119. Kapoor V, Dadey DY, Nguyen K, Wildman SA, Hoye K, Khudanyan A, Bandara N, Rogers BE, Thotala D, Hallahan DE. Tumor-specific binding of radiolabeled PEGylated GIRLRG peptide: a novel agent for targeting cancers. J Nucl Med. 2016;57:1991-7.

120. Zhao X, Yang Y, Yao F, Xiao B, Cheng Y, Feng C, Duan C, Zhang C, Liu Y, $\mathrm{Li} \mathrm{H}$, et al. Unfolded protein response promotes doxorubicin-induced nonsmall cell lung cancer cells apoptosis via the mTOR pathway inhibition. Cancer Biother Radiopharm. 2016;31:347-51.

121. Laurila N, Koivunen JP. EGFR inhibitor and chemotherapy combinations for acquired TKI resistance in EGFR-mutant NSCLC models. Med Oncol. 2015:32:205.

122. Wang G, Reed E, Li QQ. Molecular basis of cellular response to cisplatin chemotherapy in non-small cell lung cancer (Review). Oncol Rep. 2004;12:955-65

123. Tan CS, Gilligan D, Pacey S. Treatment approaches for EGFR-inhibitorresistant patients with non-small-cell lung cancer. Lancet Oncol. 2015;16:e447-59.
124. Chen W, Do KC, Saxton B, Leng S, Filipczak P, Tessema M, Belinsky SA, Lin Y. Inhibition of the hexosamine biosynthesis pathway potentiates cisplatin cytotoxicity by decreasing BiP expression in non-small-cell lung cancer cells. Mol Carcinog. 2019;58:1046-55.

125. Di S, Fan C, Yang Y, Jiang S, Liang M, Wu G, Wang B, Xin Z, Hu W, Zhu $Y$, et al. Activation of endoplasmic reticulum stress is involved in the activity of icariin against human lung adenocarcinoma cells. Apoptosis. 2015;20:1229-41.

126. Wang Z, Du T, Dong X, Li Z, Wu G, Zhang R. Autophagy inhibition facilitates erlotinib cytotoxicity in lung cancer cells through modulation of endoplasmic reticulum stress. Int J Oncol. 2016;48:2558-66.

127. Huang Y, Xiao Z, Guan Z, Shen Y, Jiang Y, Xu X, Huang Z, Zhao C. A lighttriggered self-reinforced nanoagent for targeted chemo-photodynamic therapy of breast cancer bone metastases via ER stress and mitochondria mediated apoptotic pathways. J Control Release. 2020;319:119-34.

128. Korpanty G, Smyth E, Carney DN. Update on anti-angiogenic therapy in non-small cell lung cancer: are we making progress? J Thorac Dis. 2011:3:19-29.

129. McKeage MJ, Jameson MB, Investigators ASSG. Comparative outcomes of squamous and non-squamous non-small cell lung cancer (NSCLC) patients in phase II studies of ASA404 (DMXAA) - retrospective analysis of pooled data. J Thorac Dis. 2010;2:199-204.

130. Shash E, Peccatori FA, Azim HA Jr. Optimizing the use of epidermal growth factor receptor inhibitors in advanced non-small-lung cancer (NSCLC). J Thorac Dis. 2011;3:57-64

131. Ma X, Guo W, Yang S, Zhu X, Xiang J, Li H. Serum GRP78 as a tumor marker and its prognostic significance in non-small cell lung cancers: a retrospective study. Dis Markers. 2015;2015:814670.

132. Zhu X, Lin MCM, Fan W, Tian L, Wang J, Ng SS, Wang M, Kung H, Li D. An intronic polymorphism in GRP78 improves chemotherapeutic prediction in non-small cell lung cancer. Chest. 2012;141:1466-72.

\section{Publisher's Note}

Springer Nature remains neutral with regard to jurisdictional claims in published maps and institutional affiliations.
Ready to submit your research? Choose BMC and benefit from:

- fast, convenient online submission

- thorough peer review by experienced researchers in your field

- rapid publication on acceptance

- support for research data, including large and complex data types

- gold Open Access which fosters wider collaboration and increased citations

- maximum visibility for your research: over $100 \mathrm{M}$ website views per year

At $\mathrm{BMC}$, research is always in progress.

Learn more biomedcentral.com/submissions 